\title{
La inseguridad residencial por problemas económicos en España comparada con el entorno europeo
}

\author{
Juan A. Módenes \\ Universitat Autònoma de Barcelona. Departament de Geografia \\ Centre d'Estudis Demogràfics \\ juanantonio.modenes@uab.cat
}

\section{Resumen}

Normalmente, se piensa que España es un país de alta estabilidad por lo que se refiere a la residencia, sin embargo, según la European Quality of Life Survey, más de 1,2 millones de hogares creían que abandonarían su vivienda a corto plazo por problemas económicos en 2011. El artículo analizará esta inseguridad residencial en España, que es mayor que en Europa por los motivos siguientes: $a$ ) mayor inseguridad transversal; $b$ ) mayor heterogeneidad interna en contra de los grupos más vulnerables, y $c$ ) mayor peso de los grupos más vulnerables. El caso español es próximo al francés y al italiano, pero se aleja mucho de los casos alemán y sueco, países en que las personas están más seguras en su vivienda independientemente de su situación. El artículo acaba mostrando que la alta inseguridad residencial puede ejercer un impacto negativo sobre el desarrollo y los planes vitales de los hogares jóvenes. Por último, se propone la transmisión intergeneracional de seguridad residencial como un rasgo, con fecha de caducidad, del sistema residencial español.

Palabras clave: inseguridad residencial; España; Europa; método de descomposición

Abstract: Housing Insecurity Due to Affordability Problems in Spain: A comparison with the European Context

Spain is usually considered as a high-stable country in terms of duration of residence. Nevertheless, according to the 2012 wave of the European Quality of Life Survey, more than 1.2 million households thought they were likely to be forced to move because they could not afford their homes. This paper aims to study the level of housing insecurity in Spain, which is among the highest in Europe because: a) baseline housing insecurity is higher; $b$ ) the internal heterogeneity of insecurity against vulnerable groups is larger, and 
c) the relative weight of vulnerable groups is also greater. France and Italy's levels and social distributions of housing insecurity are quite similar to Spain's, whereas Germany and Sweden are in a much better position because their households feel more secure regardless of their social status. This paper argues that high housing insecurity impinges negatively upon the life course of young households. Finally, it is suggested that the Spanish system of intergenerational transmission of housing security is likely to disappear in the near future.

Keywords: housing insecurity; Spain; Europe; decomposition method

\author{
Sumario \\ 1. Introducción 5. Discusión y conclusiones \\ 2. Marco teórico Reconocimientos \\ 3. Fuentes de datos y metodología Referencias bibliográficas
}

4. Resultados

\title{
1. Introducción
}

Tradicionalmente, España ha sido considerado un país de baja movilidad domiciliaria y de alta estabilidad residencial. En efecto, cuando se ha comparado con otros países occidentales (Long, 1991), la proporción de hogares que efectuaban un movimiento residencial era muy baja. Módenes (1998) la estimó para los años ochenta en menos de un 5\%, lo que equivalía a menos de tres mudanzas a lo largo de la vida, siempre que las condiciones del momento se mantuviesen. Esta pequeña intensidad en el cambio de vivienda coincidió con el momento álgido del modelo de propiedad. En efecto, propiedad y estabilidad residencial están conectados tanto a nivel micro (Mulder, 1993) como a nivel macro (Allen et al., 2004). En España, ha sido fácil poner en la misma cadena causal el predominio de la propiedad, la baja intensidad del cambio residencial, la elevada duración en cada vivienda y una mayor seguridad residencial. Sin embargo, esta cadena se está rompiendo (Módenes, 2015) y en este artículo veremos cómo lo hace por el último eslabón. En 2011, más de 1,2 millones de hogares pensaban que podrían abandonar su vivienda a corto plazo por problemas económicos.

Una movilidad residencial baja tiene varias consecuencias. En el lado negativo, están los problemas para una constitución familiar fluida debido al retraso de la emancipación residencial (Módenes, 1998) o la falta de incentivos de los desempleados para moverse por la dificultad de encontrar vivienda de alquiler accesible (Barceló, 2007). Los efectos positivos se pueden deducir de las consecuencias negativas que la literatura anglosajona (Astone y McLanahan, 1994) atribuye a un alto número de cambios de vivienda; por ejemplo: la baja movilidad iría asociada a un valor cívico más elevado, a comunidades urbanas locales más estables e integradas o a un mejor desempeño infantil en la escuela. A nivel de las familias, la estabilidad residencial favorece el pleno desarrollo 
de los hogares (Módenes y López-Colás, 2004). Por todo ello, podría decirse que el sistema residencial español y, en general, los sistemas residenciales sureuropeos deberían tener ciertos efectos sociales positivos, porque, a pesar de las dificultades en el acceso a la vivienda (Allen et al., 2004), la difusión de la propiedad garantizaría una elevada estabilidad a la larga.

Sin embargo, la crisis económica ha dejado a multitud de españoles pagando hipotecas insostenibles o con contratos de alquiler poco estables, y muchos de ellos sufriendo además precariedad laboral y social (Foessa, 2012), por lo que su seguridad residencial se ha resentido. Como analizaremos en este artículo, España es actualmente uno de los países europeos con mayor riesgo subjetivo de cambio de vivienda a corto plazo, por problemas para afrontar su coste económico (sea una hipoteca o la renta de un alquiler).

El artículo medirá un indicador subjetivo de inseguridad residencial en España y la diferencia negativa con el resto de Europa. Se utilizará para ello información sobre percepción del riesgo de perder la vivienda obtenida de la European Quality of Life Survey (Eurofound, 2012). Dilucidaremos si la mayor inseguridad de los españoles se debe a un mayor riesgo generalizado o a una composición social más desfavorable. Además, este artículo argumenta que debemos cuestionar la correlación entre inmovilidad residencial e inclusión social. La no movilidad no debe confundirse con seguridad residencial. Muchos hogares no se mueven, pero pueden padecer la incertidumbre sobre si podrán mantener su vivienda en los próximos meses y sobre si podrán seguir teniendo acceso a la red social y familiar de proximidad, tan importante para el sistema de bienestar español.

\section{Marco teórico}

Desde Rossi (1955), el cambio de vivienda se explica por las características, las preferencias y el desarrollo vital de individuos y hogares. El triunfo de este paradigma basado en el curso de vida (Clark y Huang, 2003) fue un gran avance, porque implantó una racionalidad sociodemográfica al cambio residencial (housing choice) (Edwards, 1983; Clark y Dieleman, 1996) y facilitó su modelización (Mulder, 1996). En efecto, a partir de Rossi, las ciencias sociales dejaron de interpretar la movilidad residencial como una respuesta social desorganizada a los problemas que afectaban a las ciudades, como había hecho la ecología humana de entreguerras (McKenzie, 1924).

A pesar del cambio de paradigma, el mismo Rossi reconoció, en su clásico estudio sobre Filadelfia, que seguía habiendo un gran número de movimientos no voluntarios o forzados (un 39\% del total). Otros autores posteriores siguieron encontrando rastros de esta movilidad involuntaria, aunque la apartaran del enfoque analítico principal. Lo hacían porque estaba más allá del control individual o de la familia (Sabagh et al., 1969) y no podía ser explicada por un modelo en dos fases de insatisfacción residencial, es decir, que explicara la decisión de moverse y la selección del destino (Speare, 1974). Según Speare, los movimientos forzados eran una parte de los movimientos sin expresión 
previa de deseo de movilidad (para él, un 30\% del total). Clark y Onaka (1983) señalaron la influencia de los factores institucionales en los movimientos forzados, algo que reemprenderemos en conclusiones. Ellos, como ya habían hecho Quigley y Weinberg (1977), mostraron que la frontera entre voluntariedad e involuntariedad puede ser borrosa; por ejemplo: cuando se trata de movilidad por motivos de salud. Por eso, los movimientos forzados serían más frecuentes al final del ciclo de vida. Según Clark y Onaka, llegarían en esa fase a un $30 \%$. La relación con la tenencia aparecía como otro factor importante. Según Kendig (1984), la mayor parte de los movimientos forzados que encontró (un $13 \%$ del total) tenían que ver con inquilinos que por algún motivo no podían continuar en la misma vivienda.

A partir de mediados de los años ochenta, la movilidad residencial no planeada volvió a ser estudiada específicamente (Forrest, 1987). Se empezó a tener en cuenta trayectorias complejas y no lineales para analizar el curso de vida, lo que, desde el punto de vista teórico, facilitó el análisis de movimientos producidos por accidentes en la trayectoria vital (Speare y Goldscheider, 1987). Además, los estudios clásicos anteriores se habían basado en contextos geográficos y sociales muy específicos: países occidentales, clases medias y entornos urbanos (Edwards, 1983; Kearns y Smith, 1994).

El cambio de vivienda forzado es actualmente objeto de estudio habitual y comprende todos aquellos movimientos no gobernados por la agencia humana (Kull et al., 2015). También ha crecido el interés por los movimientos no forzados pero que se generan en contextos de grandes restricciones sociales y económicas (Coley et al., 2014; Newman, 2008; Bruch y Mare, 2012). En países anglosajones, los problemas más frecuentes tienen que ver con pagar el alquiler o la hipoteca de la vivienda (Desmond et al., 2015), como ya había apuntado Kendig (1984). La movilidad forzada incrementa la probabilidad de establecer trayectorias de alta movilidad, porque es probable que el nuevo destino obligado sea una vivienda inadecuada (Wiesel, 2014). Según Desmond y Shollenberger (2015), una de cada ocho personas que vivían de alquiler han sufrido un cambio forzado (por desahucio u otro motivo) en los dos años anteriores en la ciudad de Milwaukee.

No toda la insatisfacción y la inseguridad residencial se traducen necesariamente en cambio de vivienda. Según la literatura occidental, la relación entre ambos términos sí es intensa y positiva, y sigue siendo cierta en determinados entornos y países (De Groot et al., 2011, para el caso de Holanda), pero no es una relación universal (Lu, 1999). Ya Duncan y Newman (1976) encontraron que menos de la mitad de los que esperaban moverse lo hacían realmente. Para la literatura no occidental, es evidente que una baja movilidad no implica necesariamente una ausencia de problemas (Fang, 2006). En contextos residenciales donde los hogares no tienen muchas opciones o no hay mucha libertad de elección, una alta insatisfacción o inseguridad puede ir asociada a una baja movilidad. Esto demuestra lo complejo de las interacciones entre inseguridad y cambio de vivienda, entre intenciones y movimientos (Lu, 1998 y 1999). En ese caso, la relación sería menos directa que para la fecundidad (Fahlén y Oláh, 2015). 
La literatura apunta actualmente que los indicadores de movilidad residencial no muestran obligatoriamente una satisfacción o una inseguridad residencial, aunque dichos aspectos están relacionados: la inseguridad residencial puede considerarse el temor a un cambio no deseado de vivienda - la perspectiva de este artículo-, pero también el temor a no poder realizar un cambio necesario. En un contexto en que la clase o el estrato social pierden importancia (Forrest y Kennett, 1997), la percepción de inseguridad tiene un componente individual muy importante. Esta sensación negativa aislada respecto a la relación con la vivienda puede influir en otras esferas de la vida familiar: proyectos reproductivos, mantenimiento de redes familiares y sociales, inserción laboral, etcétera. Aunque los efectos del cambio residencial, y principalmente de la inestabilidad residencial no voluntaria, sobre otras esferas vitales ha sido frecuentemente analizado (Heller, 1982; Astone y McLanahan, 1994; Drukker et al., 2005; Desmond y Perkins, 2014), no lo ha sido tanto la inseguridad residencial, previa a un eventual movimiento forzado (Hulse y Saugeres, 2008). A pesar de que, en el presente artículo, no podremos analizar el impacto probable que la percepción de inseguridad residencial pueda tener sobre otras esferas sociodemográficas, esta relación potencial justifica su estudio. Los indicadores de riesgo de movilidad no deseada nos ofrecen un panorama, nuevo y complementario, de la inseguridad sociodemográfica de los hogares, cada vez más común (Beck, 1992). Según Campbell et al. (2013), la inseguridad surge cuando los residentes no pueden planificar sus vidas con cierta antelación porque su estancia en la vivienda se ve amenazada por factores financieros, por una tenencia no estable o porque el tipo de alojamiento no se adecúa a las normas convencionales o culturales. Este enfoque nos aproxima a hogares con problemas de inseguridad que no pueden ser captados por indicadores estructurales que miden los ingresos económicos, y nos traslada, desde el mero análisis del riesgo a perder la vivienda, a una exploración de la intensidad de la inseguridad de los hogares para llevar a cabo sus planes vitales (Chan y Tweedie, 2015). La inseguridad residencial, al ser subjetiva, conecta con la psicología y la salud (Nettleton y Burrows, 1998), va asociada al sentimiento de miedo a quedarse sin casa (Fitchen, 1992), de caer en la exclusión social (Kennett y Mizuuchi, 2010; Lévy-Vroelant, 2010) y es parte de la inseguridad existencial u ontológica (Hiscock et al., 2001; Hulse y Saugeres, 2008).

La inseguridad residencial es multidimensional. Hulse y Saugeres (2008) identificaron seis dimensiones acerca de ese aspecto: falta de privacidad, falta de sentido de pertenencia, falta de confort físico, movilidad residencial forzada, inestabilidad residencial y vulnerabilidad residencial. Este artículo se refiere a las dos últimas. Sin duda, la inseguridad residencial se encuentra en el cruce de los problemas económicos de los hogares con los de posesión o control de la vivienda (Deidda, 2015). Ambas dimensiones son importantes, aunque solo la segunda es necesaria. En el caso de España, la propiedad completa sin pagos pendientes de la vivienda puede compensar las dificultades económicas de las personas mayores (Puga, 2004) y servir de base para un envejecimiento en el lugar (Bosch, 2006; Fernández-Carro, 2013), y ha facilitado el apoyo de estas 
generaciones a sus descendientes durante la crisis (Andrés y Ponce de León, 2013). La precariedad económica de los mayores puede ser compatible con su seguridad residencial (Kemeny, 2005).

La inseguridad residencial está muy unida al estatus de tenencia (Hulse y Saugeres, 2008), especialmente con el compromiso de pagos de larga duración. Los desahucios son un caso extremo de traslado forzado por problemas de control de la vivienda, pero no solo la inseguridad residencial va asociada a esos momentos dramáticos, sino que también actúa en etapas anteriores, y no necesariamente desemboca en un movimiento forzado; por ejemplo: la presión que sobre el hogar ejerce tener que cumplir con los pagos de la hipoteca (Forrest y Kennett, 1997; Nettleton y Burrows, 1998; Cairney y Boyle, 2004). En general, el acceso a la propiedad totalmente pagada se asocia cada vez más a una mayor seguridad final, mientras que el alquiler ha ido perdiendo posiciones (Elsinga et al., 2007). La crisis ha exacerbado estas tendencias, porque muchas de las personas que han perdido su casa en propiedad por desahucio han ido a parar al alquiler privado, el de mayor inseguridad (Bone, 2014).

En nuestro análisis empírico, se espera encontrar en España, tras los años de crisis, una alta percepción del riesgo de movilidad residencial forzada. Este riesgo de movilidad inminente será superior al cambio residencial efectivo, por lo que ofrecerá una visión más completa, y preocupante, de la inseguridad residencial existente aquí. Será un buen punto de partida para reflexionar sobre su impacto en otras esferas de la vida de los hogares españoles. Vamos a completar otras contribuciones sobre este tema en España, pero que se han centrado más en el concepto de exclusión social (Paniagua Caparrós y Cortés Alcalá, 1997; Cortés Alcalá, 1997 y 2005). Recientemente, se ha explorado el concepto de inseguridad residencial, asociado a las tenencias inadecuadas y la metodología ETHOS (García Luque, 2013; Brándle y García Luque, 2013).

Se espera hallar una importante heterogeneidad social y por tipo de tenencia en perjuicio de los hogares más frágiles, aunque debe de existir un cierto nivel de inseguridad residencial transversal a toda la población. Se presume que España tendrá más inseguridad residencial que otros países europeos, porque aquí la crisis ha precarizado más a la población. Esclareceremos si la mayor inseguridad residencial en España se extiende a todos los hogares, se debe a que en el país hay un mayor número de hogares vulnerables o se trata de una combinación de ambos motivos. Extenderemos al estudio del riesgo de cambio de viviendo forzado el enfoque comparativo internacional habitual en otros estudios sobre movilidad residencial y migraciones internas en España (López Gay, 2004; Módenes y López-Colás, 2004).

\section{Fuentes de datos y metodología}

Se han explotado los microdatos de la European Quality of Life Survey (EQLS) (Eurofound, 2014), una encuesta internacional enfocada a la comparación de variables objetivas y subjetivas de bienestar económico y social de la población 
Tabla 1. Tamaños muestrales nacionales de la European Quality of Life Survey 2012

\begin{tabular}{lccc}
\hline $\begin{array}{c}\text { Estados miembros } \\
\text { de la UE }\end{array}$ & $\begin{array}{c}\text { Entrevistas } \\
\text { completadas }\end{array}$ & $\begin{array}{c}\text { Estados no miembros } \\
\text { de la UE }\end{array}$ & $\begin{array}{c}\text { Entrevistas } \\
\text { completadas }\end{array}$ \\
\hline Alemania & 3.055 & Serbia & 1.002 \\
Austria & 1.032 & Croacia & 1.001 \\
Bélgica & 1.013 & Islandia & 1.000 \\
Bulgaria & 1.000 & Kosovo & 1.076 \\
Checa, Rep. & 1.012 & Montenegro & 1.000 \\
Chipre & 1.006 & Macedonia & 1.006 \\
Dinamarca & 1.024 & Turquía & 2.035 \\
Eslovaquia & 1.000 & Total no UE & \\
Eslovenia & 1.008 & & \\
España & 1.512 & & \\
Estonia & 1.002 & \\
Finlandia & 1.020 & \\
Francia & 2.270 & \\
Grecia & 1.004 & & \\
Hungría & 1.024 & \\
Irlanda & 1.051 & & \\
Italia & 2.250 & & \\
Letonia & 1.009 & \\
Lituania & 1.134 & & \\
Luxemburgo & 1.005 & & \\
Malta & 1.001 & & \\
Países Bajos & 1.008 & & \\
Polonia & 2.262 & & \\
Portugal & 1.013 & & \\
Reino Unido & 2.252 & & \\
Rumanía & 1.542 & & \\
Suecia & 1.007 & & \\
Total UE & 35.516 & & \\
\hline
\end{tabular}

Fuente: Eurofound, EQLS 2012. Sampling (https://www.eurofound.europa.eu/surveys/egls/2011/sampling).

europea (Eurofound, 2012). Hasta ahora, se han realizado tres ediciones (2003, 2007 y 2012), y a finales de 2017 estarán disponibles los primeros resultados de la de 2016. En esta investigación, se ha trabajado básicamente con la edición 2012 y se ha realizado alguna referencia puntual a la de 2007. La encuesta se llevó a cabo en 34 países, los 28 que en aquel momento pertenecían a la Unión Europea más otros 7 países europeos. La muestra conjunta es de 43.636 individuos (tabla 1), mientras que las muestras nacionales oscilan entre 1.000 y 3.000 entrevistados (en España, fueron 1.512). El trabajo de campo de esta edición se llevó a cabo durante el año 2011, cuando la crisis económica estaba entrando en su fase más aguda, por lo que, en el análisis empírico, se usará esta fecha como referencia temporal. 
La cuestión clave de la EQLS para este estudio es la siguiente: «¿En qué medida cree que es probable o improbable que usted tenga que dejar su vivienda en los próximos 6 meses porque no pueda pagarla?» (cuestionario en castellano, pregunta Y11_Q20). Esta pregunta tiene 4 opciones de respuesta directa: «Muy probable», «Bastante probable», «Bastante improbable», «Muy improbable», más "No sabe» y "No contesta». Siguiendo a Amendola et al. (2015), hemos agrupado las respuestas "Muy probable» $\mathrm{y}$ «Bastante probable» para explorar la inseguridad residencial de los hogares, dado que contestar «Bastante probable» ya implica una fuerte incertidumbre por parte de los hogares. Se ha asumido que esta probabilidad subjetiva equivale a un indicador de alta inseguridad residencial. Emplearemos la expresión riesgo de movilidad forzada u otras similares. Hay que insistir en que la información recogida con esta pregunta es una percepción subjetiva de riesgo y no una medida objetiva del riesgo en sí, ni tampoco mide la intensidad real de la pérdida de vivienda a causa de problemas económicos.

La suma de las dos categorías de "probable» es de un 6,97\% de la muestra española. Las respuestas de «No sabe» y «No contesta» fueron dadas en España por un 3,35\% adicional del cuestionario. Esto significa que la magnitud estudiada de la inseguridad es un mínimo y que el valor real probablemente esté por encima. Las variables independientes consideradas son país, año, edad, sexo, estructura del hogar, actividad laboral, nacionalidad y tenencia de la vivienda. Las variables sociodemográficas han sido escogidas de acuerdo con las dimensiones explicativas más mencionadas por la literatura.

Como en la EQLS no hay ninguna variable identificativa de la persona de referencia o principal, se ha procedido a estimar las principales características que se le asociarían. La encuesta es contestada en cada hogar por la persona mayor de 18 años que tiene más próximo su cumpleaños al día de la entrevista, y esa persona ofrece además información relevante sobre el resto de miembros del hogar. La persona de referencia se ha identificado con base en criterios internos desarrollados en el Centre d'Estudis Demogràfics para mejorar la comparación de información censal basados en el informe del Grupo de Canberra sobre estadísticas de ingresos a nivel de hogar (United Nations, Canberra Group, 2011). Ello ha permitido incorporar como variables estructurales la edad y la actividad laboral de la persona de referencia.

La metodología utilizada consta de dos fases. En la primera, básicamente descriptiva, se empieza comparando el indicador subjetivo agregado de riesgo de movilidad de España con los de los países de la EQLS. La exploración de los porcentajes de hogares en riesgo de movilidad forzada en relación con las distintas variables independientes se ha realizado en comparación con un conjunto de seis países (denominados UE-6 durante el artículo) representativos por su peso demográfico y/o por ser característicos de diferentes sistemas residenciales europeos. Estos países son: Alemania, Francia, Italia, Polonia, el Reino Unido y Suecia. Los dos primeros son característicos del sistema residencial continental; Italia es una muestra del modelo del sur de Europa; Polonia, del de los países del Este de Europa; el Reino Unido, del sistema liberal anglosajón, y Suecia, del 
nórdico (Allen et al., 2004; Hoekstra, 2005; Mandic, 2012; Van der Heijden, 2013; Módenes et al., 2013b).

La segunda parte del análisis empírico se basa en una descomposición de la diferencia entre el indicador de inseguridad residencial de España respecto al conjunto UE-6 e individualmente con cada uno de ellos. En efecto, la simple comparación de la inseguridad residencial total entre países puede llevar a errores de interpretación, porque se trata de un indicador bruto, es decir, que no está controlado por su estructura por edad, ni por el resto de estructuras o variables de composición de la población que son relevantes. La estandarización, típica del análisis demográfico, logra este objetivo. De esta forma, se logra comparar de manera neta las intensidades entre dos o más poblaciones, dicho de otro modo, se pueden comparar los «efectos tasas» suponiendo que las poblaciones comparadas mantienen las mismas estructuras de composición. Sin embargo, también es interesante conocer y medir cómo influyen las diferencias reales de composición de las poblaciones. Esto se consigue al pasar de la estandarización a los métodos de descomposición de tasas. Esta opción mantiene tanto el análisis de las propensiones como el de las estructuras reales en el análisis, se basa menos en supuestos discutibles sobre la selección de estándares de población y posiblemente es más útil a la hora de buscar una aplicabilidad social y política a sus resultados (Canudas, 2003). Se ha utilizado el método de descomposición de Das Gupta (Das Gupta, 1993; Menacho, 2002; Canudas, 2003; Chevan y Sutherland, 2009). Este método permite analizar la diferencia entre dos tasas o indicadores de intensidad de dos poblaciones (o de una misma población en dos momentos diferentes), separando la parte de la diferencia atribuible a la diferente composición de las poblaciones en función de variables estructurales escogidas (efecto composición) y, por otro lado, la parte de la diferencia atribuible efectivamente a intensidades desiguales (efecto tasa). El efecto composición puede especificarse a su vez por cada una de las variables estructurales introducidas. La notación general, citando a Chevan y Sutherland (2009), para comparar el comportamiento de dos poblaciones con dos variables estructurales sería:

$$
x-X=(\text { efecto } \mathrm{T})+(\text { efecto } \mathrm{I})+(\text { efecto } \mathrm{J})
$$

En la ecuación, $x$ y $X$ son dos indicadores globales de dos poblaciones distintas que queremos comparar, efecto $T$ o efecto tasa es la parte de la diferencia explicada por las diferencias de intensidad estandarizada, efecto I es la diferencia entre $x$ y $X$ explicada por la diferente composición de la variable de estructura I, mientras que efecto J es la diferencia entre $x$ y $X$ explicada por la diferente composición de la variable de estructura J.

En nuestro análisis, el indicador que se pretende comparar es el porcentaje de hogares que manifiestan riesgo inmediato de cambio de vivienda. Una parte de las diferencias se explicará por las propensiones diferentes de cada país y otra parte, por la presencia desigual en cada país de los colectivos más en riesgo. Como variables estructurales, se han seleccionado tres representativas de las 
dimensiones sociodemográficas que más explican la inseguridad residencial: tipo de tenencia de la vivienda (sin pagos regulares, propiedad con hipoteca, alquiler privado), situación de actividad laboral (trabajando, desempleado, otra) y nacionalidad (español, no español). Las categorías, especialmente las de tenencia, quedan justificadas por el análisis de la literatura y el marco teórico empleado. El efecto composición de otras variables se considera mínimo, pero será recogido en los distintos valores en que se descompone la diferencia de los indicadores iniciales.

Como colofón, se ha realizado la descomposición de las diferencias entre España y el grupo UE-6 en función de la edad de la persona de referencia del hogar: menores o iguales a 45 años y mayores de 45 años. El límite 45 permite disponer de dos grupos de tamaño suficiente para los análisis, así como identificar mejor aquellos hogares que todavía están inmersos en diferentes trayectorias activas de hogar y que pueden resultar más perjudicados por una eventual inseguridad residencial.

\section{Resultados}

\subsection{Indicadores agregados}

Un 7\% de los hogares españoles de 2011 creían que era probable o muy probable que tuvieran que cambiar de vivienda por motivos económicos en los siguientes seis meses. Bastantes más que el 5,4\% de hogares que, en 2007, indicaron este temor. En total, en 1,26 millones de hogares se sentía la incertidumbre de no saber si se seguiría viviendo en la misma casa. A raíz de la crisis, la inseguridad residencial se ha convertido en un fenómeno bastante frecuente que no está limitado a familias en situaciones de extrema fragilidad económica o social, por lo que una parte significativa de la sociedad española no tiene la estabilidad residencial necesaria para realizar planes vitales a largo plazo. Estos datos completan las estadísticas de desahucios por ejecución hipotecaria o por impago de rentas, que, en total, arrojan cifras en torno a las 60.000 pérdidas de vivienda anuales (Consejo General del Poder Judicial, 2016).

Si comparamos los porcentajes, vemos que España se sitúa en una posición relativamente desfavorable. De los países de la UE, España es el sexto con mayor proporción de riesgo (figura 1). Muy por delante están Grecia (13,3\%) y Chipre (11,7\%), seguidos de Irlanda y Portugal. Este grupo está formado por países mediterráneos (faltaría Italia) más Irlanda, que, como sabemos, también han padecido un estallido de una burbuja inmobiliaria y se caracterizan por la ausencia de un parque de vivienda social que pueda amortiguar la inseguridad de los hogares más frágiles (Scanlon et al., 2014), excesivamente dependientes de la propiedad (Pareja y Sánchez, 2016). Dinamarca es un caso sorprendente que no estudiaremos aquí, aunque, según Hanan (2012), era uno de los países donde más habían crecido los desahucios al principio de la crisis, junto con España y Hungría. También es cierto que, en la franja entre el 5\% y el 7\%, se encuentran otros once países, entre ellos, Francia, Italia o el Reino Unido, por 
Figura 1. Proporción de hogares con riesgo de cambiar de vivienda por no poder pagarla en los próximos seis meses. Países de la Unión Europea, 2011

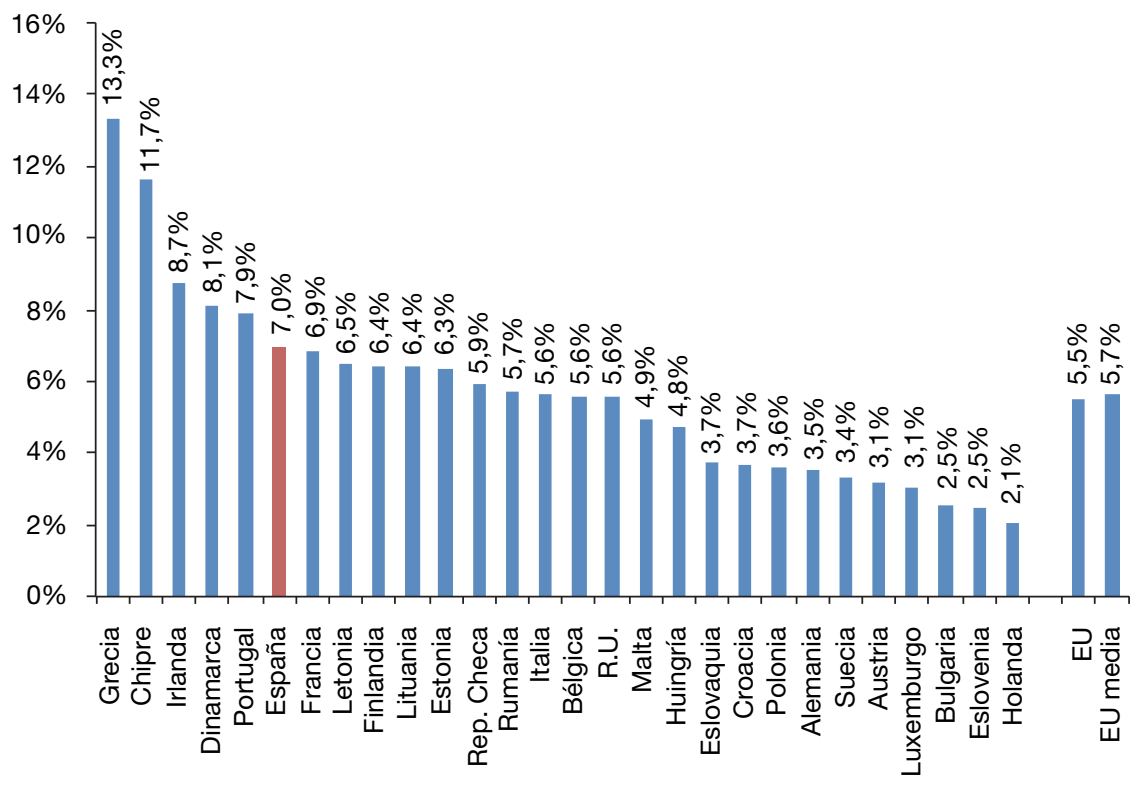

Fuente: EQLS, 2012. Elaboración propia.

lo que el nivel de España es frecuente. Entre los países con menos percepción de riesgo de movilidad residencial forzada están Holanda, Luxemburgo, Austria, Suecia y Alemania, con sistemas residenciales que tienden a una mayor equidad, facilidad y seguridad en el acceso a la vivienda, especialmente en alquiler, además de ser económicamente más estables (Kemeny, 1995; Van der Heijden, 2002). También encontramos países de la Europa del Este, donde la seguridad económica de la población es menor, pero que cuentan con la herencia de un parque casi universal de propiedad producto de la privatización del antiguo parque de vivienda social (Clapham, 1995; Mandic, 2012), aunque las generaciones más jóvenes se encuentren con dificultades de acceso (Módenes et al., 2013b). El valor medio de todos los países recogidos en la EQLS es de un $5,7 \%$, porcentaje que refleja lo relativamente habitual de las situaciones de riesgo de pérdida de la vivienda y la inseguridad residencial.

La última gran crisis económica ha provocado, entre 2007 y 2011, un incremento generalizado de la inseguridad residencial en la mayoría de los países analizados (figura 2). La inseguridad aumentó más del doble en Grecia y Chipre. En Irlanda, Portugal y Francia, la subida también fue considerable. En este contexto, España experimentó un aumento moderado de un 5,4\% a un 7\%, dado que el nivel de 2007 ya era bastante alto. El promedio de los países analizados subió de un $4,1 \%$ a un $5,7 \%$. La inseguridad residencial se 
Figura 2. Proporción de hogares con riesgo de cambiar de vivienda por no poder pagarla en los próximos seis meses. Países de la Unión Europea, 2007 y 2011

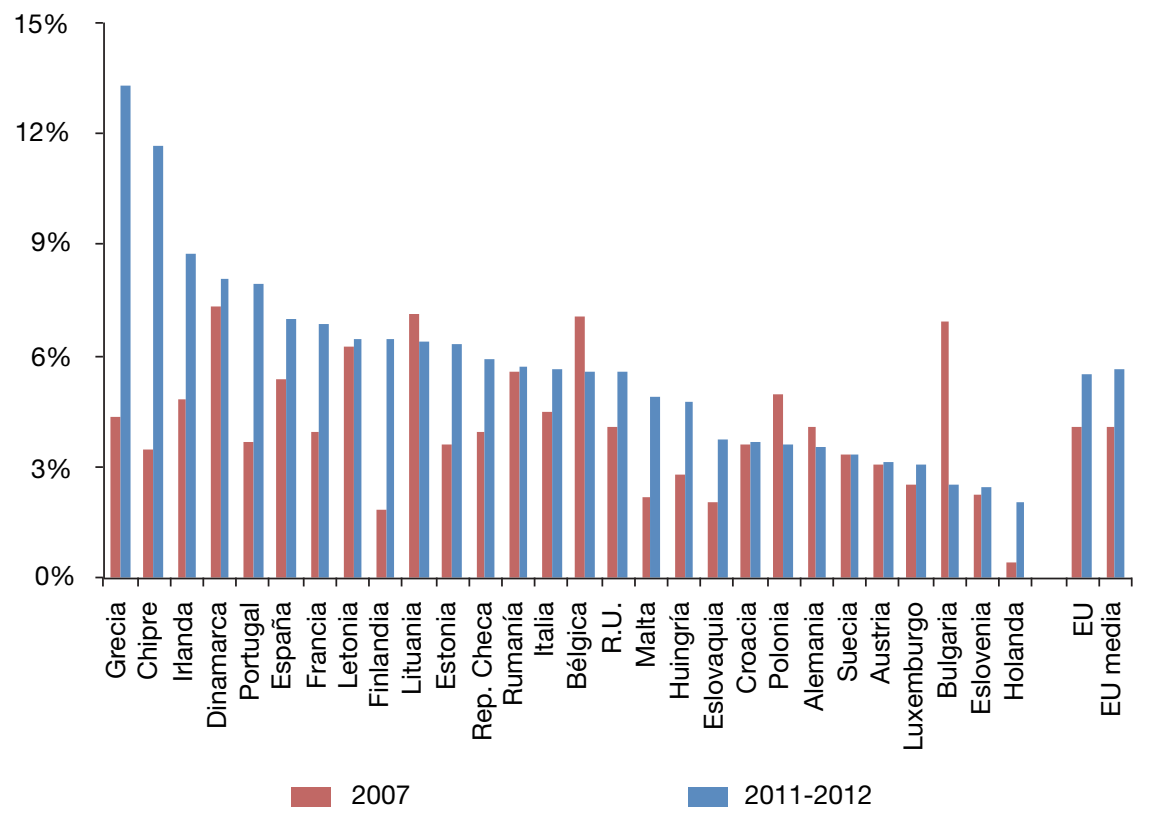

Fuente: EQLS, 2007 y 2012. Elaboración propia.

mantuvo constante durante este período convulso en los países que contaban con los niveles más bajos, lo que sugiere la relación directa entre implicación pública en los sistemas de provisión y la seguridad residencial de la población en períodos problemáticos. La crisis ha provocado una mayor heterogeneidad entre países europeos (Pittini et al., 2015), también en la seguridad residencial.

Como se apuntó anteriormente, la inseguridad residencial es mayor que la movilidad residencial en España. Teniendo en cuenta la tasa bruta de movilidad residencial, en España cambiaba de vivienda anualmente un 5,4\% de las personas (Eurostat, Census Hub, 2011 Census Database). Es posible que una parte importante de las que expresan inseguridad engrosen los hogares que cambian de vivienda, pero no tiene por qué haber una relación directa.

La figura 3 representa la relación entre el riesgo de cambio forzado de vivienda y la denominada tasa bruta de movilidad residencial en referencia a los países de la Unión Europea. Dicha tasa está entendida como la proporción de personas que cambian de vivienda en el año anterior al censo. En efecto, la relación está lejos de ser lineal (figura 3). En algunos países, ambas tasas son altas, como Finlandia, Francia, Dinamarca y Portugal, y también Chipre. En teoría, estos serían los países en que más inseguridad corresponde a 
Figura 3. Relación entre el indicador de inseguridad residencial y la tasa de movilidad residencial. Países de la Unión Europea, 2011

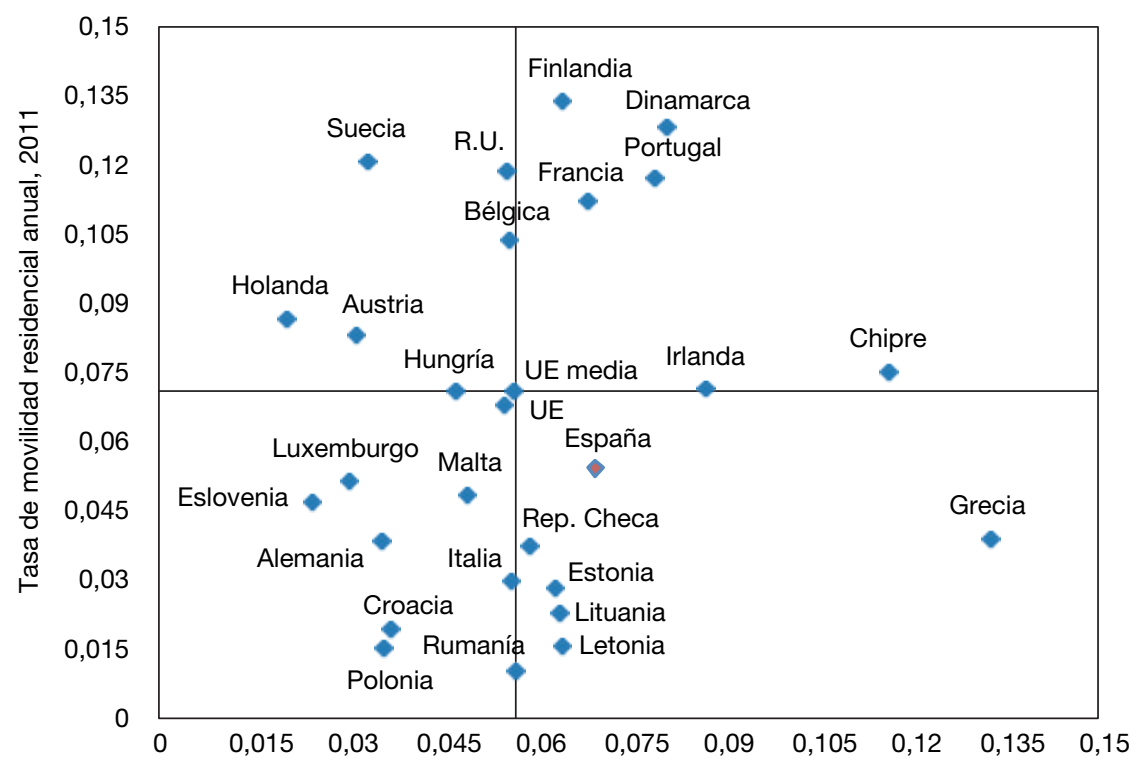

Riesgo de movilidad res. Forzada (6 meses, 2011)

Fuente: Riesgo de movilidad: EQLS, 2012. Movilidad residencial: Census Hub, Eurostat, 2011. Elaboración propia.

mayor movilidad. En el otro extremo, tenemos países con baja inseguridad y baja movilidad residenciales. Alemania representa bien esta seguridad estable y deseable, y Polonia, Croacia o Eslovenia están cercanas a la posición alemana. Como se decía antes, tienen alta seguridad y pocos cambios de vivienda por el predominio de la propiedad privatizada, pero es probable que la heterogeneidad social interna sea mayor que en Alemania.

Por otro lado, hay países donde la rotación residencial es elevada, pero coincide con una baja percepción de riesgo de movilidad forzosa. Países donde el alquiler tiene una presencia importante, que acarrea un mayor nivel de movilidad residencial, pero con poca conflictividad. Suecia sería el representante principal. En Holanda y Austria, también hay poca inseguridad, pero la movilidad es algo más baja. Bélgica y el Reino Unido tendrían un alto nivel de movilidad, pero con un mayor grado de inseguridad.

España está entre los países cuya población cambia poco de vivienda, pero padece una alta inseguridad residencial relativa. Se confirma que una alta inseguridad residencial no tiene que ir acompañada por muchos traslados, lo que sí es normal en otros países occidentales. Grecia sería un representante extremo de esta falta de correlación, que también afecta a algunos países del Este (países 
bálticos, República Checa y Rumanía) e Italia, aunque la percepción de riesgo es más baja. Irlanda y Chipre estarían en la transición con países de alta inseguridad y alta movilidad residenciales.

\subsection{Heterogeneidad sociodemográfica}

Esperamos encontrar que la percepción de inseguridad residencial es heterogénea socialmente. Los hogares más frágiles serán más inseguros. Esta heterogeneidad en la inseguridad se ve potenciada por el aumento de los grupos vulnerables (Martínez García, 2014).

La inseguridad residencial es máxima en las edades jóvenes y menor en los hogares más maduros (figura 4). La vejez, por suerte, no va asociada a mucha inseguridad residencial. España tiene más heterogeneidad por edad que los países UE-6. Los jóvenes españoles viven en riesgo residencial con bastante más frecuencia que en otros países (más de un $12 \%$ frente a un $8 \%$ de media en los países comparados), mientras que las personas ancianas tienen un nivel equivalente (entre un $2 \%$ y un 3\%). Mientras que estas diferencias por edad pueden responder a una lógica de ciclo de vida, es más probable que se trate también de disimilitudes estables entre generaciones, con cierta independencia de la edad.

El tipo de hogar más seguro residencialmente es la pareja, mientras que los hogares monoparentales presentan un mayor riesgo. En España, la heterogeneidad es más intensa en contra de los hogares monoparentales (más de un 14\%). La inseguridad residencial es ligeramente mayor en España en el resto de categorías, excepto en las parejas solas.

El contexto geográfico y urbanístico circundante no es una variable especialmente determinante de la heterogeneidad interna. En UE-6 y España, la inseguridad residencial es parecida en todos los ámbitos, si acaso existe algo más en los espacios urbanos más densos. En España, esta heterogeneidad geográfica es algo más marcada.

Las dimensiones sociodemográficas que analizamos a continuación son más determinantes de los niveles de heterogeneidad por lo que respecta a la inseguridad residencial. Se trata de la tenencia y la situación laboral, que nos acercan a la seguridad ontológica de los hogares necesaria para el desarrollo de su curso de vida y sus redes de relación. La tercera variable que analizaremos es el origen migratorio, especialmente importante en el caso de España.

En todos los países, el alquiler privado va asociado a un riesgo de movilidad forzada mucho más alto. Recordemos que nuestro interrogante, en principio, no recoge el riesgo estructural a este tipo de tenencia debido a la finalización de los contratos, sino que recoge la percepción del riesgo por no poder hacer frente al coste económico de la renta. Este riesgo es más alto que en la otra categoría con compromiso de pagos: la propiedad con hipotecas. En las dos categorías sin obligación de pagos regulares, el riesgo es mínimo, más todavía en la propiedad sin hipoteca, apenas un $2 \%$. Por lo tanto, la inseguridad residencial se relaciona muy directamente con el coste económico regular de la vivienda. Pues bien, 
Figura 4. Indicador de inseguridad residencial teniendo en cuenta diferentes variables de estructura sociodemográfica. España y UE-6, 2011

Edad persona principal

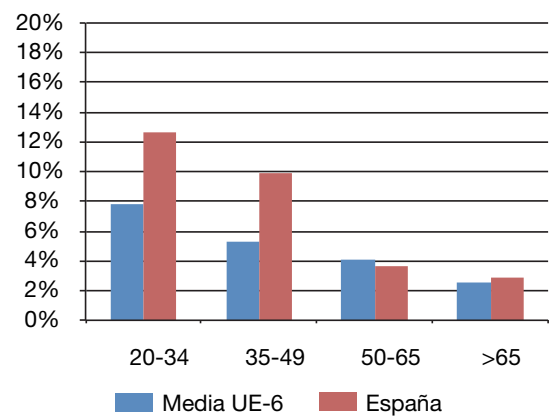

Entorno urbano

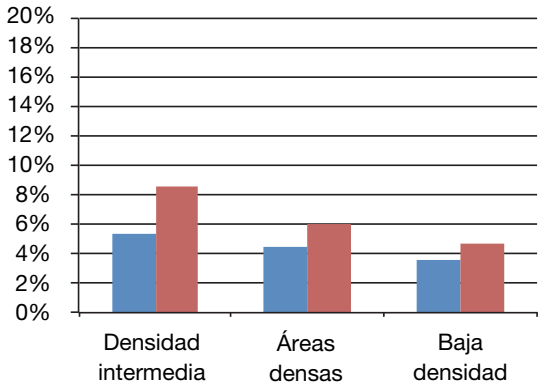

Media UE-6

Actividad laboral

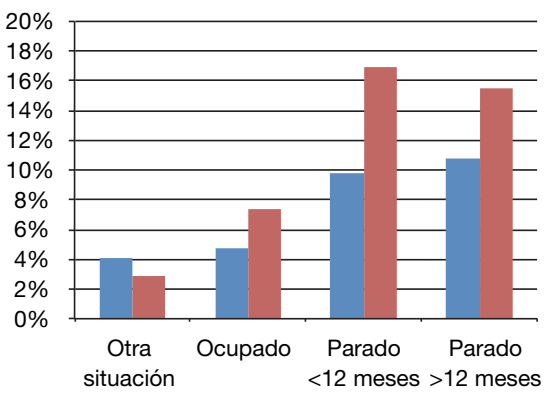

Tipo de hogar

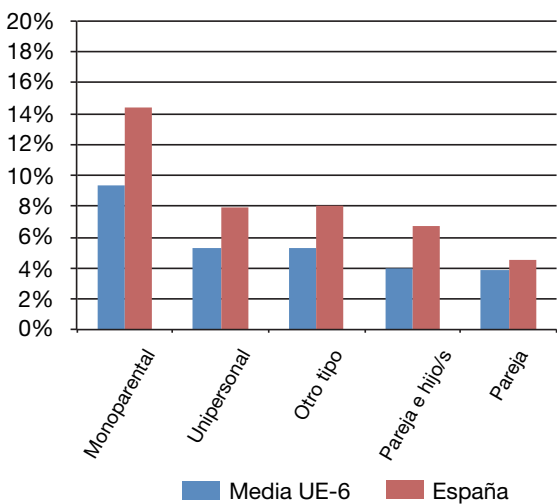

Tenencia de la vivienda

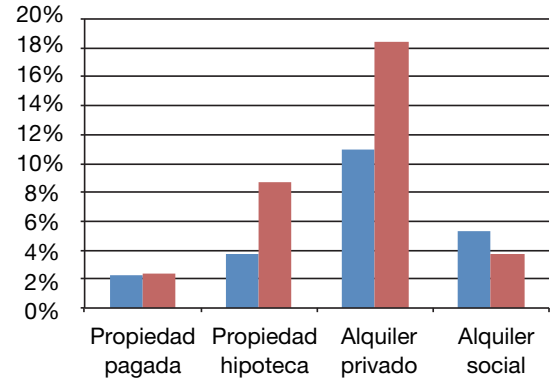

UE-6

España

Nacionalidad

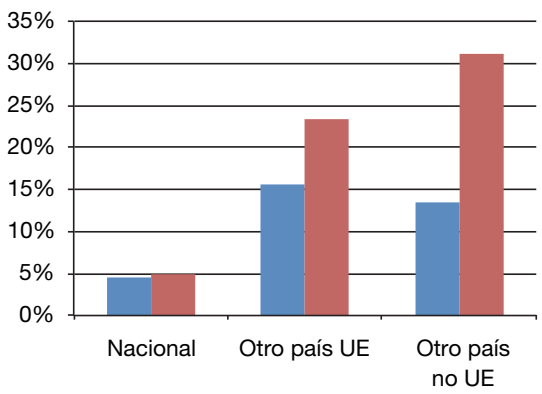

UE-6: Alemania, Francia, Italia, Polonia, el Reino Unido y Suecia.

Fuente: EQLS, 2012. Elaboración propia. 
en España hay más heterogeneidad entre las distintas tenencias en perjuicio de las dos con pagos regulares; los niveles alcanzados están bastante por encima de las de los otros grandes países de la UE. Concretamente, más de un 18\% de los hogares en alquiler privado reportaron riesgo de movilidad forzada en los siguientes seis meses. A distancia quedan los que pagan hipotecas con casi un $9 \%$, la mitad de riesgo.

Si se citan las cifras absolutas, en 2011, unos 400.000 hogares que vivían en alquiler sentían un alto riesgo de tener que moverse en los siguientes seis meses por problemas en los pagos. Este riesgo lo percibían unos 500.000 hogares con hipotecas pendientes (aunque la probabilidad es menor, hay muchos más hogares hipotecados que en alquiler). Pero todavía quedarían 350.000 hogares que, a pesar de vivir en tenencias menos comprometidas, siguen sintiendo un riesgo inmediato de movilidad. Es decir, no están seguros en su vivienda. Ello nos recuerda que la mala situación económica de los hogares muchas veces supera la supuesta estabilidad de la tenencia para determinar la existencia de inseguridad residencial.

En efecto, la percepción de inseguridad residencial también es muy sensible a la fragilidad económica de los hogares, analizada aquí con la situación de desempleo. En los grandes países europeos, es una de las dimensiones más importantes para explicar la heterogeneidad en los niveles de inseguridad residencial, más aún si el paro es de larga duración. La inseguridad de los hogares cuyas personas principales están desempleadas alcanza niveles del 10\%. También aquí se reproduce y se intensifica esta dimensión de heterogeneidad. Alrededor de un $16 \%$ de los cabezas de hogar parados tienen riesgo de perder su casa de manera casi inmediata. Es destacable que la inseguridad residencial no elude a las personas principales con ocupación. La percepción del riesgo de movilidad forzada está aproximadamente en la media del conjunto de la población. En efecto, sería una prueba de que el trabajo no asegura actualmente tanto la estabilidad social a los hogares (Climent, 2015). Los hogares en otras situaciones de actividad, principalmente jubilados en edades avanzadas, corren un riesgo más bajo.

Ser inmigrante dificulta el acceso a una vivienda de calidad (Vono y Bayona, 2012; Módenes et al., 2013a). Y también incrementa la percepción de inseguridad residencial, además de ser un factor cada vez más importante de las migraciones internas en Europa (Finney y Catney, 2012; Recaño y De Miguel, 2012; Recaño, 2016). En UE-6, la inseguridad residencial de los habitantes nacidos en otro país triplica la de los ciudadanos de esos países, pero España exacerba aún más esta dimensión de heterogeneidad interna: los residentes no comunitarios multiplican por seis (hasta un 30\%) el nivel de inseguridad residencial de los españoles, mientras que los residentes de otros países comunitarios lo multiplican por cinco. Curiosamente, los nacionales españoles reproducen el riesgo de movilidad forzada que se encuentra en los nacionales dentro de cada país UE-6: un 5\%. Indudablemente, ser inmigrante es un factor clave que explica la inseguridad residencial en España, más aún que en el resto de Europa. En ellos, se unen la condición de migrante, la instalación en tenencias con compromisos excesivos de pagos y la precariedad laboral. 
Como hemos visto, casi todas las categorías sociodemográficas sensibles de España son más inseguras residencialmente que las europeas. Muestran un riesgo igual de movilidad forzada la franja de edad 50-65, los no activos y los propietarios sin pagos pendientes (las tres categorías tienden a referirse a hogares maduros), así como los que viven en alquiler social (una categoría minúscula en España). Significativamente, la población de nacionalidad española también presenta niveles bajos, solo algo más altos que los europeos. Esto indica que la inseguridad residencial afecta bastante más que en UE-6 a las categorías más frágiles y vulnerables, las cuales están más alejadas respecto del resto de la población ${ }^{1}$.

\subsection{Descomposición de las diferencias entre España y UE-6}

Ha quedado demostrado que el riesgo inmediato más elevado de movilidad residencial de España se explica por la mayor tendencia de la población espanola vulnerable a sentir inseguridad residencial. Ahora intentaremos poner en relación esta mayor intensidad del riesgo con los factores de composición, es decir, si también tiene un papel la diferente estructura sociodemográfica de España en relación con la población vulnerable. Para ello, utilizaremos el método de descomposición de tasas de Das Gupta y mediremos los efectos relativos de las variables de estructura escogidas (efecto composición) y de las propensiones (efecto tasa).

Las variables de estructura escogidas para estudiar los efectos de composición han aparecido como las más determinantes en términos de heterogeneidad y, al mismo tiempo, son las más coherentes desde el punto de vista teórico: la tenencia de la vivienda y la situación de actividad, que son los dos grandes polos que explican la fragilidad residencial, y, además, la nacionalidad, que se ha constituido en el gran eje de diferenciación social en España.

Ya se ha dicho que el indicador de percepción de movilidad forzada inmediata de España es significativamente más elevado que el de UE-6 (un 7,0\% frente a más de un 4,8\%, 2,1 puntos de diferencia). Con el método Das Gupta, descompondremos esta diferencia en la aportación de las diferencias de estructura y también obtendremos cuál es el efecto neto de la diferencia de propensiones a la inseguridad residencial.

El efecto composición agregado es tan importante como el efecto tasa en la diferencia entre la inseguridad residencial española y la de UE-6, ya que 1,1 puntos de los 2,1 totales de la diferencia se explican por efectos composicionales (tabla 2). Es decir, España tiene una estructura sociodemográfica

1. Hasta aquí no se había hecho referencia a la variable sexo. Como la EQLS no ofrece ninguna definición de los hogares encabezados por mujeres, no hemos querido profundizar en ello, a pesar de que contamos con una estimación propia. La posibilidad de que la suma de pequeños errores llevara a grandes problemas en la definición de la inseguridad residencial por sexo aconseja no ir más allá. Sin embargo, se puede decir que, en Europa, normalmente, los hogares encabezados por mujeres son más inseguros residencialmente. Pero los datos de España no lo confirman. 
Tabla 2. Descomposición de las diferencias entre el indicador de inseguridad residencial de España y de diferentes países europeos, 2011. Método de descomposición de Das Gupta

\begin{tabular}{lrrrrrrr}
\hline & \multicolumn{6}{c}{ Diferencia de España respecto a... } \\
\cline { 2 - 8 } & UE-6 & Francia & Alemania & Italia & Polonia & Unido & Suecia \\
\hline Efecto estructura tenencia & $0,0 \%$ & $-0,6 \%$ & $-0,6 \%$ & $0,6 \%$ & $1,5 \%$ & $0,0 \%$ & $-0,6 \%$ \\
Efecto estructura nacionalidad & $0,5 \%$ & $0,2 \%$ & $0,2 \%$ & $0,9 \%$ & $0,3 \%$ & $0,2 \%$ & $0,6 \%$ \\
Efecto estructura actividad & $0,5 \%$ & $0,4 \%$ & $0,6 \%$ & $0,7 \%$ & $0,4 \%$ & $0,4 \%$ & $0,6 \%$ \\
\hline Efecto total estructura & $1,1 \%$ & $0,0 \%$ & $0,1 \%$ & $2,2 \%$ & $2,2 \%$ & $0,6 \%$ & $0,7 \%$ \\
Efecto tasa & $1,1 \%$ & $0,1 \%$ & $3,3 \%$ & $-0,9 \%$ & $1,2 \%$ & $0,8 \%$ & $3,0 \%$ \\
Diferencia bruta con España & $2,1 \%$ & $0,1 \%$ & $3,4 \%$ & $1,3 \%$ & $3,4 \%$ & $1,4 \%$ & $3,6 \%$ \\
\hline
\end{tabular}

Fuente: elaboración propia a partir datos EQLS, 2012.

significativamente más propensa a sufrir inseguridad residencial. Las tres variables de estructura no colaboran por igual a esta situación. La distribución por tenencia es neutra, el método de descomposición empleado no detecta ningún efecto al comparar con el agregado UE-6. La distribución por actividad laboral sí influye notablemente ( 0,5 puntos porcentuales), porque hay más hogares cuyas personas principales están en paro. Y la distribución por nacionalidad también contribuye otros 0,5 puntos, porque hay más hogares con miembros extranjeros que el conjunto de UE-6.

El efecto tasa nos dice que 1,1 puntos de los 2,1 totales de diferencia se explican porque, en España, la inseguridad residencial es mayor independientemente de las características del hogar. Es decir, si seleccionamos dos hogares de características iguales, uno español y otro de UE-6, el español tendría más inseguridad residencial. Otra manera de interpretarlo es en forma de tasa estandarizada. Si España tuviese la misma estructura sociodemográfica (tenencia de la vivienda, actividad laboral y nacionalidad) que UE-6, el porcentaje de hogares que percibirían un riesgo inminente de movilidad forzada sería de un $5,9 \%$ frente a un 4,8\% de UE-6.

Este mismo ejercicio lo podemos realizar en comparaciones uno a uno de España con cada otro gran país de UE-6. Efectivamente, el grupo UE-6 es heterogéneo, puesto que comprende países con distintos sistemas residenciales, es decir, diferentes sistemas de provisión y de interrelación evolutiva con los contextos social, económico y político (Hoekstra, 2013). El indicador de inseguridad residencial es, en consecuencia, bastante heterogéneo, como vimos al principio del análisis empírico.

Italia forma parte del sistema residencial del sur de Europa (Allen et al., 2004; Hoekstra, 2005; Baldini y Poggio, 2014). Esto debería quizá traducirse en una cierta proximidad de comportamiento en cuanto a la inseguridad residencial. Sin embargo, el indicador italiano es 1,3 puntos porcentuales más bajo. Básicamente porque el efecto de composición es claramente favorable a Italia. Hay menos hogares en tenencias de riesgo, menos hogares en paro y, sobre todo, menos hogares compuestos por extranjeros. El efecto composición 
completo explica 2,2 puntos porcentuales. Sin embargo, el efecto tasa es claramente favorable a España, que ya es decir. Un hogar español de las mismas características que uno italiano, tendría un riesgo 0,9 puntos más bajo que el italiano. En definitiva, ambos casos son bastante diferenciados, tanto socialmente como en el riesgo residencial, lo que muestra una cierta heterogeneidad interna del grupo sureuropeo (Azevedo, 2016).

Curiosamente, el caso francés es más próximo al español. El indicador general de percepción de riesgo es muy semejante, solo presenta una décima de diferencia. El efecto composición es nulo, pero es producto de que, en Francia, las estructuras de actividad laboral y nacionalidad son más favorables, no mucho, mientras que la estructura de tenencia de los hogares franceses es bastante desfavorable, porque hay más presencia de hogares con compromiso de pagos. La proximidad entre ambos países se refuerza porque el efecto tasa es mínimo, apenas hay una décima porcentual de diferencia a favor de Francia. En Francia, la percepción de la inseguridad residencial a nivel individual es casi la misma que aquí.

El caso alemán está muy alejado del nuestro. El indicador alemán es 3,4 puntos porcentuales más bajo que el español. La mayor parte de esta diferencia se explica directamente por el efecto tasa. Es decir, en Alemania, cualquier hogar, independientemente de sus características, va a tener una sensación de inseguridad residencial mucho más baja que un hogar español. El efecto composición es muy bajo, pero hay efectos contrarios según el tipo de estructura. Las estructuras de actividad laboral (sobre todo) y de nacionalidad son muy favorables en Alemania, pero no la de tenencia de la vivienda, ya que el alquiler privado es predominante. Pero, como hemos dicho, la reducida inseguridad a nivel individual (probablemente gracias a la protección institucional y legal) compensa esa composición desfavorable de la situación residencial de los hogares.

Polonia se aleja también a su favor de la situación española. Tras la caída de los regímenes comunistas, parecía que los sistemas residenciales de los países del Este se encaminaban hacia el modelo de propiedad de los países del sur. Sin embargo, la inseguridad residencial no ha seguido el mismo camino. Ambos componentes, composicional y de tasa, contribuyen a ello. La estructura de tenencia es muy favorable, puesto que pocos hogares tienen que hacer frente a pagos periódicos. En esto, Polonia e Italia se asemejan. Las estructuras de actividad laboral y de nacionalidad igualmente favorecen la mayor seguridad residencial. El efecto tasa también contribuye bastante, no tanto como en Alemania, por lo que, entre dos hogares de idénticas características sociodemográficas, el polaco tendría una menor sensación de inseguridad residencial que el español.

Suecia es el caso más alejado del español. Su patrón de heterogeneidad de los niveles de inseguridad residencial respecto a España es muy semejante al alemán. La principal diferencia es que, en Suecia, hay un menor efecto de la estructura de nacionalidad, lo que reduce su nivel respecto al español en 0,6 puntos porcentuales. Su estructura de actividad laboral también favorece su 
baja inseguridad residencial. Como Alemania, su estructura de tenencia es desfavorable, pero el efecto favorable de las otras dos dimensiones estructurales basta para que el efecto de composicional total contribuya en 0,6 puntos a establecer la diferencia. También como en el caso alemán, la principal fuente de heterogeneidad con España se encuentra directamente en el efecto tasa (3 puntos porcentuales).

El Reino Unido se sitúa en una posición intermedia. El efecto tasa le favorece y también el efecto composición, especialmente por lo que respecta a la estructura de actividad y de nacionalidad. Por otro lado, el efecto de la estructura de tenencia es neutro, lo que le asemeja al caso español.

En resumen, el país con el indicador global más bajo y alejado de España es Suecia (junto con Alemania y Polonia). El país más distanciado de España por el efecto tasa es Alemania a favor de esta, mientras que solo Italia está peor que España. La estructura de tenencia de España es más favorable que la de Francia, Suecia y Alemania, pero muy alejada de la de Polonia, la más favorable. La estructura de actividad española es claramente más desfavorable que la del resto de países, mientras que el efecto de la nacionalidad varía más según el país.

Aunque el efecto tasa y el efecto total de composición tienen una participación parecida en explicar la diferencia del indicador de percepción de la movilidad forzada de España respecto al conjunto de UE-6, este patrón no se reproduce en la comparación de España con cada país individualmente. El más próximo es el Reino Unido. En Italia y Polonia, el efecto composición explica principalmente sus mejores indicadores agregados. En Suecia y, sobre todo, en Alemania, la mayor seguridad residencial está explicada sobre todo por el efecto tasa. El caso de Francia sería el más semejante al español, aunque existen efectos de estructura contrarios.

\subsection{Descomposición de las diferencias según la edad de la persona principal}

En el apartado 4.2, hemos visto que la heterogeneidad en la inseguridad residencial entre España y los países UE-6 tenía una dimensión demográfica muy clara, porque no solo todos los hogares jóvenes son más propensos a sentir esa inseguridad que los de edad más avanzada, sino que los españoles lo son bastante más que el resto de europeos (un 12,0\% de los hogares jóvenes españoles contra un 7,6\% de UE-6). En el análisis anterior, no tenía mucho sentido añadir el efecto de la estructura por edad, porque son bastante semejantes. No iban a aportar un efecto de composición significativo.

Sin embargo, sí parece relevante acotar la comparación internacional por grandes conjuntos generacionales. Llamamos hogares jóvenes a los encabezados por personas de, como máximo, 45 años. Por lo tanto, en este caso, joven es un concepto relativo y se refiere a las primeras fases de desarrollo del hogar, especialmente en lo que se refiere a las etapas de consolidación residencial, laboral y de realización del proyecto reproductivo. Si la inseguridad residencial puede afectar al resto de esferas de desarrollo vital, es sobre todo en un hogar de esa franja de edad. 
Tabla 3. Descomposición de las diferencias entre el indicador de inseguridad residencial de España y UE-6 por grandes grupos de edad de la persona principal del hogar, 2011. Método de descomposición de Das Gupta

\begin{tabular}{lccc}
\hline & Total & $<=45$ & $>45$ \\
\hline Efecto estructura tenencia & $0,0 \%$ & $-0,1 \%$ & $0,0 \%$ \\
Efecto estructura nacionalidad & $0,5 \%$ & $0,8 \%$ & $0,2 \%$ \\
Efecto estructura actividad & $0,5 \%$ & $0,6 \%$ & $0,1 \%$ \\
\hline Efecto total estructura & $1,1 \%$ & $1,3 \%$ & $0,3 \%$ \\
Efecto tasa & $1,1 \%$ & $3,9 \%$ & $-0,2 \%$ \\
\hline Diferencia bruta & $2,1 \%$ & $4,4 \%$ & $0,1 \%$ \\
\hline
\end{tabular}

UE-6: Alemania, Francia, Italia, Polonia, el Reino Unido y Suecia.

Fuente: EQLS, 2012. Elaboración propia.

La mayor inseguridad residencial de los jóvenes españoles es incontestable (tabla 3). La diferencia con los países europeos se explica tanto por un efecto de composición desfavorable como, sobre todo, por un efecto de mayores tasas. Las estructuras españolas son desfavorables en tenencia, actividad laboral y nacionalidad. Y el efecto tasa es muy desfavorable: 3,9 puntos porcentuales de diferencia. Este es el principal factor que explica la mayor inseguridad residencial. Cualquier hogar joven español es más probable que sienta bastante más riesgo de perder su casa que otro hogar joven europeo de las mismas características. Por lo que respecta al efecto de composición, las estructuras de actividad y de nacionalidad marcan la pauta, es decir, la mayor presencia del paro y el mayor número de hogares jóvenes compuestos de inmigrantes. Sin embargo, la estructura de tenencia es neutra, lo que vuelve a dejar de manifiesto el papel protector que ha tenido tradicionalmente el sistema residencial español.

Por lo que respecta a los hogares de edad avanzada, las circunstancias son muy distintas. La diferencia bruta del indicador general es de apenas una décima porcentual, es decir, los hogares maduros y viejos españoles tienen la misma seguridad a corto plazo que los europeos. El efecto tasa es incluso sensiblemente favorable a los españoles. Si no fuera por una estructura sociodemográfica ligeramente desfavorable (especialmente la de nacionalidad), podríamos decir que los hogares de edad avanzada en España tienen incluso menos riesgo percibido de perder su casa que los europeos.

\section{Discusión y conclusiones}

El nivel de inseguridad residencial de España a raíz de la última gran crisis económica ha aumentado hasta valores realmente altos. El artículo se centra en la explicación de los factores sociodemográficos que explican esta inseguridad y no ha abordado explícitamente sus consecuencias. Sin embargo, es evidente el impacto que puede ejercer esta alta inseguridad residencial sobre otras esferas vitales, por ejemplo: el comportamiento demográfico. 
Esta posición de cabeza de España no se corresponde con su nivel de movilidad residencial. Durante toda la crisis, aunque con oscilaciones, el nivel de cambio de vivienda se ha mantenido sustancialmente por debajo del nivel observado en otros países, aunque este fenómeno también incluye, aunque desconocemos su peso, la movilidad forzada por motivos económicos. En España, la inseguridad residencial, definida como la falta de confianza en poder seguir residiendo en el mismo lugar a corto plazo, no se traduce necesariamente en un ajuste residencial. Este desajuste entre inseguridad y movilidad residencial es compartido con otros países a los que también les ha ido mal durante esta crisis, como Irlanda, Chipre y, especialmente, Grecia. La relación entre la seguridad de los hogares en su vivienda y cómo el cambio de domicilio puede actuar como válvula de ajuste, o bien, cuáles son las estrategias de permanencia a pesar de la inseguridad, restan como líneas de investigación para el futuro. Este resultado pone en duda la tradicional conexión que la literatura realiza entre la existencia de muchos desplazamientos residenciales y una alta inserción en las estructuras sociales y las redes familiares locales, porque parece evidente que los hogares que no se mueven pueden estar experimentando episodios de inseguridad residencial que entorpezcan su inserción social a largo plazo.

El mayor nivel de inseguridad residencial español es resultado de una mezcla de factores. En primer lugar, porque existe un mayor riesgo transversal en todos los hogares. En efecto, en casi todas las categorías analizadas, la inseguridad residencial percibida era mayor en España. Más grave aún, la heterogeneidad interna en España de la inseguridad residencial es más intensa y afecta negativamente a los grupos más vulnerables. Pero es que, además, estos grupos sociodemográficos más inseguros tienen un peso relativo en la población mayor que en nuestro marco de comparación: hogares en viviendas con pagos regulares comprometidos, hogares en paro y hogares con extranjeros.

Los grandes países europeos más alejados de la situación española son, por un lado, Alemania y Suecia y, por otro, Polonia. Alemania y Suecia tienen un nivel de inseguridad residencial percibida mucho más bajo que España a escala de probabilidad individual. Además, presentan muchos menos hogares en paro, una característica de alto riesgo de inseguridad. Por otro lado, el impacto de la inmigración reciente ha sido menor, o al menos lo era en 2011. Estos factores más que compensan su estructura de tenencia ligeramente desfavorable. Por lo que respecta a Polonia, su menor inseguridad residencial se debe principalmente a su estructura sociodemográfica más favorable, sobre todo en lo que respecta a la estructura de tenencia de la vivienda. El Reino Unido se sitúa en una posición intermedia entre Alemania y Suecia, y España.

Italia y Francia presentan problemas de inseguridad residencial que los acercan a España. Francia prácticamente reproduce el indicador general de España y los efectos de tasa y composición globales son nulos, aunque la estructura de actividad favorece a Francia, que se ve compensada por la desfavorable estructura de tenencia residencial. El caso de Italia es todavía más extremo. Muestra una tasa de inseguridad residencial mejor que España, pero que se explica totalmente por la composición sociodemográfica más favorable, con 
menor presencia de hogares propensos a estar inseguros en sus viviendas. Sin embargo, las propensiones individuales son más altas que en España, lo que sitúa a Italia junto con los otros países mediterráneos que han sufrido la crisis.

La mayor inseguridad residencial de España e Italia, a las que podemos sumar Grecia, Chipre y Portugal, se explica en buena parte porque el riesgo individual a perder la casa por motivos económicos es más alto que en otros países, independientemente de la situación del hogar. El origen de este riesgo, al no ser explicado básicamente por las características del hogar, cabe atribuirlo a causas externas, relacionadas con el contexto económico del momento, pero también al institucional, legal y político. En definitiva, y concretando, a elementos estructurales del sistema residencial de esos países. Efectivamente, la crisis económica indujo el aumento de la inseguridad respecto de 2007, pero fue el marco normativo el que no impidió que se extendiera el miedo a la pérdida de la vivienda, como, por ejemplo en España, con procedimientos semiautomáticos de desahucio y lanzamiento, denunciados por las instituciones judiciales de la Unión Europea (Pérez-Lanzac, 2014). Como se sabe, el enfoque social de las políticas de vivienda basado en la protección de los residentes está bastante ausente en los países del sur de Europa (Leal, 2005 y 2009; Pareja y Sánchez, 2011 y 2015). Podemos afirmar que, a los atributos de este sistema residencial, cabe sumar el de una mayor inseguridad estructural. Como ésta es dinámica y creciente, es otro de los parámetros de cambio que nuestro sistema residencial está experimentando en los últimos años (Módenes, López-Colás, 2014; Módenes, 2015). Obviamente, la influencia del contexto institucional, legal y político no solo regula la relación del hogar con su vivienda, sino que se extiende a factores que, en este artículo, se han considerado composicionales. En efecto, cabe atribuir también a la influencia de la esfera pública la intensidad del paro o la normalidad con que hogares vulnerables tienen que afrontar pagos por la vivienda en el mercado privado no regulado. Por todo ello, saber cómo los distintos sistemas regulatorios nacionales actúan sobre la seguridad residencial y obtener como resultado un catálogo crítico de buenas prácticas políticas son líneas claras de desarrollo de esta investigación.

La mayor inseguridad residencial de España y otros países del sur de Europa se concentra en los hogares jóvenes. Precisamente en estas edades se llevan a cabo las principales transiciones en los proyectos familiares, reproductivos o laborales. Que más del 12\% de los hogares encabezados por personas de menos de 34 años muestren miedo a perder su vivienda a corto plazo no puede augurar nada bueno en el desarrollo vital de estos hogares, y más si pensamos que antes de esa edad se han formado relativamente pocos hogares, precisamente por los problemas de viabilidad de una formación temprana. De hecho, solo el $60 \%$ de los hogares de menos de 34 años respondió que era muy improbable que perdieran su casa en los siguientes seis meses. Ciñéndonos a los impactos demográficos, por ejemplo, es muy complicado en esa situación plantearse tener un hijo. Sería otro factor que agregar al complejo causal de la creciente infecundidad en España (Esteve et al., 2016). Además, el sistema de bienestar español se basa en buena parte en la proximidad residencial de los miembros de 
la red familiar de apoyo (Flaquer, 2004). La confianza en un acceso continuado a esta red se pone en duda si entra en la ecuación la inseguridad residencial. Volviendo a los componentes de la mayor inseguridad residencial de los jóvenes, se trata otra vez de una combinación de efectos de composición (mayor número de hogares en situaciones de riesgo) y, sobre todo, de efectos de tasa (mayor propensión individual). Es decir, de nuevo la importancia del contexto institucional y legal.

Por suerte, la inseguridad residencial de los hogares españoles de edad avanzada es bastante más baja, y se encuentra a un nivel equiparable, o incluso mejor, a la de los países europeos. El predominio de la propiedad de viviendas sin pagos pendientes, adquiridas en condiciones más favorables que las actuales, ha protegido a muchos de estos hogares que, objetivamente, son socioeconómicamente más vulnerables. En otros países, los hogares de edad avanzada son menos vulnerables, pero su inserción residencial les protege menos.

Esta estabilidad de los mayores se ha transferido a los hijos, en una transmisión intergeneracional de seguridad residencial importantísima, que hay que añadir a otras formas de transferencia en el interior de las redes familiares, tan frecuentes en el sur de Europa (Poggio, 2008). En efecto, la inseguridad residencial de los jóvenes españoles aún habría sido mayor sin la protección ofrecida por la seguridad residencial de sus padres, que ha comportado para muchos de aquellos la renuncia a formar hogar propio. El retraso de la emancipación se puede entender en muchos casos, entre los grupos más frágiles, como una vía de transferencia de esa seguridad. Como argumenta Azevedo (2016), la extensión hasta edades avanzadas de la corresidencia con los padres por parte de jóvenes activos laboralmente se puede interpretar como una opción residencial más, al mismo nivel que la elección de comprar o alquilar una vivienda independiente. Crisis en la inserción en la vida adulta, emancipación tardía e inseguridad residencial se pueden unir en un complejo de interrelaciones.

Esta transferencia intergeneracional no se replicará en el futuro. Cuando los hogares jóvenes actuales alcancen edades más avanzadas en el futuro, muy probablemente sus condiciones residenciales objetivas no serán tan favorables como las de los hogares coetáneos actuales, porque las hipotecas durarán hasta edades más avanzadas y es posible que muchos hogares vulnerables hayan seguido en el mercado de alquiler privado. Cuando vuelva a presentarse otra de las crisis económicas recurrentes, no será posible transmitir la seguridad residencial a los hijos de manera tan generalizada.

Obviamente, las políticas de vivienda no solo deben garantizar el acceso a ella, sino también facilitar en lo posible la estabilidad de las personas en sus domicilios, impidiendo la movilidad forzada e incrementando la seguridad residencial (Cano y Etxezarreta, 2014). ¿Cómo es posible esto último? A la vista de los resultados de nuestra investigación, la estabilidad económica es un factor obvio al disminuir los hogares en riesgo económico. La integración adecuada de los inmigrantes en la sociedad española también ayudará a reducir los niveles agregados de inseguridad. Sin embargo, la reducción del número 
de hogares potencialmente vulnerables en tenencias muy vinculadas a pagos periódicos sin protección pública se antoja necesaria aunque complicada, a la luz de la evolución reciente. Menos evidente, pero tan importante o más, es que la acción pública también reduzca ese «efecto tasa», esa mayor inseguridad transversal de España. Sin duda, la mejora del contexto regulatorio ayudaría extraordinariamente para que existiera más protección de los hogares vulnerables, que deben entrar cada vez más en el sector de alquiler, y para que estos puedan desarrollar sus proyectos vitales reduciendo la incertidumbre.

\section{Reconocimientos}

Este artículo se ha realizado gracias a la financiación ofrecida por el proyecto $\mathrm{I}+\mathrm{D}+\mathrm{I}$ titulado Movilidad geográfica y acceso a la vivienda: España en perspectiva internacional (CSO2013-45358-R), correspondiente a la convocatoria 2013 del Programa Estatal de Investigación, Desarrollo e Innovación orientada a los Retos de la Sociedad, cuyos investigadores principales son el autor y Joaquín Recaño. Igualmente, el autor agradece a Julián López-Colás y Antonio López-Gay, del Centre d'Estudis Demogràfics, y a Hernán Villarraga, de la Universidad Regional Amazónica Ikiam, de Ecuador, las sugerencias aportadas a raíz de la lectura de una versión preliminar de este artículo. Además, el autor agradece al Centre d'Estudis Demogràfics el apoyo material y logístico para esta investigación, así como los comentarios y las sugerencias de los evaluadores anónimos.

\section{Referencias bibliográficas}

Allen, J.; Barlow, J.; Leal, J.; Maloutas, T. y Padovani, L. (2004). Housing and Welfare in Southern Europe, 16. Nueva Jersey: John Wiley \& Sons.

Amendola, A.; Dell'Anno, R. y Parisi, L. (2015). Happiness, Inequality and Relative Concerns in European Countries, 136. CELPE-Centre of Labour Economics and Economic Policy. University of Salerno.

Andrés Cabello, S. y Ponce de LeÓn Romero, L. (2013). «Rompiendo la hucha familiar: Estado de bienestar y familia en España, en un escenario de crisis sistémica». Trabajo Social Hoy [en línea], 69, 7-20. $<$ https://doi.org/10.12960/TSH.2013.0007>.

Astone, N.M. y MCLANAHAN, S.S. (1994). «Family structure, residential mobility, and school dropout: A research note». Demography [en línea], 31 (4), 575-584. $<$ https://doi.org/10.2307/2061791>.

AzEvedO, A.B. (2016). Housing and family dynamics in Southern Europe. Barcelona: Universitat Autònoma de Barcelona. Tesis doctoral.

BACHILLER, S. (2009). «Significados del espacio público y exclusión de las personas sin hogar como un proceso de movilidad forzada». Revista Española de Investigaciones Sociológicas (REIS), 128 (1), 125-137.

BAldini, M. y Poggio, T. (2014). «The Italian housing system and the global financial crisis». Journal of Housing and the Built Environment [en línea], 29 (2), 317-334.

$<$ https://doi.org/10.1007/s10901-013-9389-7>. 
BARCElÓ, C. (2007). «La tenencia de vivienda y la movilidad laboral en la Unión Europea». Boletín Económico: Banco de España, 5, 49-56.

BECK, U. (1992). Risk society: Towards a new modernity, 17. Sage.

BONE, J. (2014). "Neoliberal nomads: Housing insecurity and the revival of private renting in the UK». Sociological Research Online, 19 (4), 14 p.

Bosch MEDA, J. (2006). «El problema de la vivienda en la vejez en Cataluña». ACE: Architecture, City and Environment, 1 (1), 80-100.

Brändle SeÑÁn, G. y García Luque, O. (2013). "Análisis y medición de la exclusión residencial». En: HERNÁNDEZ PEDREÑO, M. Vivienda y exclusión residencial. Murcia: Editum, 139.

BRUCH, E. y MARE, R.D. (2012). «Methodological issues in the analysis of residential preference, residential mobility, and neighborhood change». Sociological Methodology [en línea], 42, 103-154. $<$ https://doi.org/10.1177/0081175012444105>.

CAirney, J. y Boyle, M. (2004). "Home ownership, mortgages and psychological stress». Housing Studies [en línea], 19 (2), 161-74. <https://doi.org/10.1080/0267303032000168577>.

CAMPBEll, I.; PARKInSON, S. y WOOD, G. (2013). «The housing security consequences of underemployment». AHURI Positioning Paper, 152, 1-72.

Cano, G. y EtXezarreta, A. (2014). «La crisis de los desahucios en España: Respuestas institucionales y ciudadanas». Revista de Economía Critica, 17, 44-57.

Canudas Romo, V. (2003). Decomposition methods in demography. Amsterdam: Rozenberg Publishers. Tesis doctoral.

Chan, S. y TweEdie, D. (2015). «Precarious Work and Reproductive Insecurity». Social Alternatives, 34 (4), 5.

Chevan, A. y Sutherland, M. (2009). «Revisiting Das Gupta: Refinement and extension of standardization and decomposition». Demography [en línea], 46 (3), 429-449. <https://doi.org/10.1353/dem.0.0060>.

Clapham, D. (1995). «Privatisation and the East European housing model». Urban Studies [en línea], 32 (4-5), 679-694. <https://doi.org/10.1080/00420989550012834>.

Clark, W.A. y Dieleman, F.M. (1996). Households and housing: Choice and outcomes in the housing market. Transaction Publishers.

Clark, W.A. y Huang, Y. (2003). "The life course and residential mobility in British housing markets». Environment and Planning A [en línea], 35 (2), 323-339. $<$ https://doi.org/10.1068/a3542>.

CLARK, W.A. y ONAKA, J.L. (1983). "Life cycle and housing adjustment as explanations of residential mobility». Urban Studies [en línea], 20 (1), 47-57. $<$ https://doi.org/10.1080/713703176>.

Climent SAnjuÁn, V. (2015). «La nueva pobreza en el mercado de trabajo». Intangible Capital, 11 (2), 270-283.

Coley, R.L.; Kull, M.A.; Leventhal, T. y LynCH, A.D. (2014). «Profiles of housing and neighborhood contexts among lowincome families: Links with children's well-being». Cityscape: A Journal of Policy Development and Research, 16, 41-64.

Consejo General Del Poder Judicial (2016). Datos sobre el efecto de la crisis en los órganos judiciales.

CORTÉs AlCAlÁ, L. (1997). Hablando sobre la exclusión residencial, 41. Cáritas Española. 
- (2005). «La crisis de la vivienda». Documentación Social, 138, 81-100.

Das Gupta, P. (1993). Standardization and decomposition of rates: A user's manual, 186. US Department of Commerce, Economics and Statistics Administration. Bureau of the Census.

De Groot, C.; Mulder, C.H. y Manting, D. (2011). «Intentions to move and actual moving behaviour in The Netherlands». Housing Studies, 26 (3), 307-328. <https://doi.org/10.1080/02673037.2011.542094>.

DEIDDA, M. (2015). "Economic hardship, housing cost burden and tenure status: Evidence from EU-SILC». Journal of Family and Economic Issues [en línea], 36 (4), 531-556. <https://doi.org/10.1007/s10834-014-9431-2>.

Desmond, M. y Gershenson, C. (2016). «Housing and employment insecurity among the working poor». Social Problems [en línea], spv025. $<$ https://doi.org/10.1093/socpro/spv025>.

Desmond, M.; Gershenson, C. y Kiviat, B. (2015). "Forced relocation and residential instability among urban renters». Social Service Review [en línea], 89 (2), 227-262. $<$ https://doi.org/10.1086/681091>.

Desmond, M. y PERKIns, K.L. (2014). «Housing and Household Instability». Urban Affairs Review [en línea], 52 (3), 421-436. $<$ https://doi.org/10.1177/1078087415589192>.

Desmond, M. y Shollenberger, T. (2015). «Forced Displacement From Rental Housing: Prevalence and Neighborhood Consequences». Demography [en línea], 52,1751 . <https://doi.org/10.1007/s13524-015-0419-9>.

Dol, K.; CruZ, E.; LAMBEA, N. et al. (2016). «Regionalization of housing policies?: An exploratory study of Andalusia, Catalonia and the Basque Country».J Hous and the Built Environ [en línea]. <https://doi.org/10.1007/s10901-016-9528-z>.

DrukKer, M.; KaPlan, C. y VAN Os, J. (2005). «Residential instability in socioeconomically deprived neighbourhoods, good or bad?». Health and Place [en línea], 11 (2), 121-129. <https://doi.org/10.1016/j.healthplace.2004.02.002>.

DunCAN, G.J. y NEWMAN, S.J. (1976). «Expected and actual residential mobility». Journal of the American Institute of Planners [en línea], 42 (2), 174-186. <https://doi.org/10.1080/01944367608977718>.

Dupuis, A. y ThORNs, D. (1998). «Home, home ownership and the search for ontological security». Sociological Review [en línea], 46 (1), 24-47. <https://doi.org/10.1111/1467-954X.00088>.

EDWARDS, M. (1983). «Residential mobility in a changing housing market: The case of Bucaramanga, Colombia». Urban Studies [en línea], 20 (2), 131-145. <https://doi.org/10.1080/00420988320080281>.

Elsinga, M.; De Decker, P.; Teller, N. y Toussaint, J. (2007). Home ownership Beyond asset and security: Perceptions of housing related security and insecurity in eight European countries. Amsterdam: IOS Press.

Esteve, A.; Devolder, D. y Domingo, A. (2016). «La infecundidad en España: Tictac, tic-tac, tic-tac!!!». Perspectives Demogràfiques, 1. Centre d'Estudis Demogràfics.

Eurofound (European Foundation FOR THE IMPROVEMENT OF Living AND WORKING CONDITIONS) (2012). Quality of Life in Europe: Impacts of the Crisis. 
- (2013). Household over-indebtedness in the EU: The role of informal debts. Luxemburgo: Publications Office of the European Union.

- (2014). European Quality of Life Survey Integrated Data File, 2003-2012 [en línea]. 2. ${ }^{a}$ ed. Colchester, Essex: UK Data Archive (enero). SN: 7348. <http://dx.doi.org/10.5255/UKDA-SN-7348-2>.

Eurostat. Census Hub, 2011 Census Database [en línea]. <https://ec.europa.eu/CensusHub2>.

FAHLÉN, S. y OlÁH, L. (2015). "The impact of economic uncertainty on childbearing intentions in Europe». Families and Societies: Workin Paper Series, 36.

FANG, Y. (2006). «Residential satisfaction, moving intention and moving behaviours: A study of redeveloped neighbourhoods in inner-city Beijing». Housing Studies [en línea], 21 (5), 671-694. <https://doi.org/10.1080/02673030600807217>.

Fernández CARro, C. (2013). Ageing in Place in Europe: A Multidimensional Approach to Independent Living in Later Life. Barcelona: Universitat Autònoma de Barcelona. Tesis doctoral.

Finney, N. y Catney, G. (2012) (eds.). Minority Internal Migration in Europe. Oxford: Ashgate, Publishing. International Population Studies Series.

Fitchen, J.M. (1992). "On the Edge of Homelessness: Rural Poverty and Housing Insecurity». Rural Sociology [en línea], 57 (2), 173-193. <https://doi.org/10.1111/j.1549-0831.1992.tb00462.x>.

FLAQUER, L. (2004). «La articulación entre familia y el Estado de bienestar en los países de la Europa del sur». Papers: Revista de Sociología [en línea], 73, 27-58. $<$ https://doi.org/10.5565/rev/papers/v73n0.1105>.

FOESSA (2012). Exclusión y desarrollo social. Madrid: Cáritas Española.

FORREST, R. (1987). «Spatial mobility, tenure mobility, and emerging social divisions in the UK housing market». Environment and Planning A [en línea], 19 (12), 1611-1630. $<$ https://doi.org/10.1068/a191611>.

ForRest, R. y KENNETT, P. (1997). «Risk, residence, and the post-fordist city». The American Behavioral Scientist [en línea], 41 (3), 342-359. <https://doi.org/10.1177/0002764297041003006>.

García LuQue, O. (2013). «Cómo medir la exclusión residencial». IV Congreso REPS 2013.

HANAN, R. (2012). "The social impact of the economic crisis in Europe». Working Notes, 69, 16-20.

Heijden, H. van der (2002). «Social rented housing in Western Europe: Developments and expectations». Urban Studies [en línea], 39 (2), 327-340. <https://doi.org/10.1080/00420980120102993>.

- (2013). West European housing systems in a comparative perspective, 46. Amsterdam: IOS Press.

Heller, T. (1982). «The effects of involuntary residential relocation: A review». American Journal of Community Psychology [en línea], 10 (4), 471-492. <https://doi.org/10.1007/BF00893984>.

Hiscock, R.; Kearns, A.; Macintyre, S. y Ellaway, A. (2001). "Ontological security and psycho-social benefits from the home: Qualitative evidence on issues of tenure». Housing, Theory and Society [en línea], 18 (10), 50-66. <https://doi.org/10.1080/14036090120617>.

HOEKSTRA, J. (2005). «Is there a connection between welfare state regime and dwelling type?: An exploratory statistical analysis». Housing Studies [en línea], 20 (3), 475-495. <https://doi.org/10.1080/02673030500062509>. 
- (2013). «Housing and the welfare state: Changing perspectives and a research agenda». En: ENHR 2013 Conference "Overcoming the Crisis, Integrating the Urban Environment». Tarragona, 19-22 junio 2013. ENHR.

Hulse, K. y Saugeres, L. (2008). "Housing insecurity and precarious living: An Australian exploration». AHURI Final Report [en línea], 124, 1-51.

KEARNS, R.A. y SMITH, C.J. (1994). "The residential mobility experiences of marginalized populations». Tijdschrift voor Economische en Sociale Geografie [en línea], 85 (2), 114-129.

<https://doi.org/10.1111/j.1467-9663.1994.tb00681.x>.

KemenY, J. (1995). From Public Housing to the Social Market [en línea]. Londres: Routledge.

- (2005). "The really big trade-off between home ownership and welfare: Castles' evaluation of the 1980 thesis and a reformulation 25 years on». Housing, Theory and Society, 22 (2), 59-75.

KENDIG, H.L. (1984). «Housing careers, life cycle and residential mobility: Implications for the housing market». Urban Studies [en línea], 21 (3), 271-283. <https://doi.org/10.1080/00420988420080541>.

KennetT, P. y Mizuuchi, T. (2010). «Homelessness, housing insecurity and social exclusion in China, Hong Kong, and Japan». City, Culture and Society [en línea], 1 (3), 111-118. <https://doi.org/10.1016/j.ccs.2010.09.002>.

Kull, M.A.; COley, R.L. y LYNCH, A.D. (2015). «The roles of instability and housing in low-income families' residential mobility». Journal of Family and Economic Issues, $1-13$.

LeAl, J. (2005). «La política de vivienda en España». Documentación Social, 138, 63-80.

- (2009). «El cambio de modelo y convergencia con Europa en la política de vivienda social española». Ciudad y Territorio: Estudios Territoriales, 161-162, 489-504.

LÉVY-VROELANT, C. (2010). «Housing vulnerable groups: The development of a new public action sector». International: Journal of Housing Policy [en línea], 10 (4), 443-456. <https://doi.org/10.1080/14616718.2010.525051>.

LONG, L. (1991). «Residential mobility differences among developed countries». International Regional Science Review [en línea], 14 (2), 133-147. <https://doi.org/10.1177/016001769101400202>.

LÓPEZ GAY, A. (2004). «Intensidad y calendario de la movilidad residencial en la Unión Europea». Scripta Nova: Revista Electrónica de Geografía y Ciencia Sociales, VIII (174).

LU, M. (1998). "Analyzing migration decisionmaking: Relationships between residential satisfaction, mobility intentions, and moving behavior». Environment \& Planning A [en línea], 30 (8), 1, 473-495. <https://doi.org/10.1068/a301473>.

- (1999). «Do people move when they say they will?: Inconsistencies in individual migration behavior». Population and Environment [en línea], 20 (5), 467-488. <https://doi.org/10.1023/A:1023365119874>.

MANDIC, S. (2012). "Home ownership in post-socialist countries: Between macro economy and micro structures of welfare provision». Beyond home ownership: Housing, welfare and society. Londres: Routledge. 
Martínez García, J.S. (2014). «Cómo afecta la crisis a las clases sociales?». Político, 20, 16.

McKenZIE, R.D. (1924). "The ecological approach to the study of the human community». American Journal of Sociology [en línea], 287-301. $<$ https://doi.org/10.1086/213698>.

MenaCho, T. (2002). Los tipos de estandarización en demografia: Aplicación al estudio de las diferencias regionales de la actividad y desempleo en España, 1990-2000. Memoria de investigación presentada en el Departamento de Geografía de la Universitat Autònoma de Barcelona.

MÓDENES, J.A. (1998). Flujos espaciales e itinerarios biográficos: La movilidad residencial en el área de Barcelona [en línea]. Universitat Autònoma de Barcelona. Tesis doctoral. Mimeo. <http://ddd.uab.cat/record/127209>.

- (2015), «Cambio demográfico, formación de hogares y sistema residencial». En: Torres Albero, Cristóbal et al. (eds.). Situación social España 2015. Madrid: CIS, $127-138$.

MÓdenes, J.A.; BAYONA, J. y LÓPEZ COLÁS, J. (2013a). «Immigration and residential change in Spain». Population, Space and Place [en línea], 19 (3), 294-310. <https://doi.org/10.1002/psp.1712>.

MÓdENES, J.A.; FERnÁNDEZ-CARRO, C. y LÓPEZ-COLÁS, J. (2013b). «La formación de hogares y la tenencia de vivienda de los jóvenes en la reconfiguración de los sistemas residenciales europeos». Scripta Nova: Revista Electrónica de Geografía y Ciencias Sociales, 17, 460.

MÓDENES, J.A. y LÓPEZ-COLÁs, J. (2004). «Movilidad residencial, trabajo y vivienda en Europa». Geo Crítica / Scripta Nova: Revista Electrónica de Geografía y Ciencias Sociales, VIII, 159.

- (2014). «Cambio demográfico reciente y vivienda en España: ¿Hacia un nuevo sistema residencial?». Revista Española de Investigaciones Sociológicas (REIS), 148 (1), 103-133.

Mulder, C.H. (1993). Migration dynamics: A life course approach. Amsterdam: Thesis Publishers. $251 \mathrm{p}$.

- (1996). "Housing choice: Assumptions and approaches». Netherlands Journal of Housing and the Built Environment [en línea], 11 (3), 209-232. <https://doi.org/10.1007/BF02496589>.

NetTleton, S. y Burrows, R. (1998). «Mortgage debt, insecure home ownership and health: An exploratory analysis». Sociology of Health and Illness [en línea], 20 (5), 731-753. $<$ https://doi.org/10.1111/1467-9566.00127>.

NEWMAN, S.J. (2008). "Does housing matter for poor families?: A critical summary of research and issues still to be resolved». Journal of Policy Analysis and Management [en línea], 27 (4), 895-925. <https://doi.org/10.1002/pam.20381>.

Paniagua Caparrós, J.L. y Cortés Alcalá, L. (1997). «La vivienda como factor de exclusión social». Documentación Social, 106, 93-148.

Pareja-EASTAWAy, M. y SÁnChez-Martínez, M.T. (2011). «El alquiler: Una asignatura pendiente de la política de vivienda en España». Ciudad y Territorio: Estudios Territoriales, 167, 53-70.

- (2015). «El sistema de vivienda en España y el papel de las políticas: ¿Qué falta por resolver». Cuadernos Económicos del ICE, 90, 149-174.

- (2016). «Have the edges of homeownership in Spain proved to be resilient after the global financial crisis?». International Journal of Housing Policy, 1-20. 
PÉreZ-LanZaC, C. (2014). «El tribunal de la UE también considera abusiva la reforma de la ley hipotecaria». El País (17 julio).

Pittini, A.; GHekière, L.; Dijol, J. y Kiss, I. (2015). The state of housing in the EU 2015. Bruselas: Housing Europe.

Poggio, T. (2008). "The intergenerational transmission of home ownership and the reproduction of the familialistic welfare regime». Families, Ageing and Social Policy [en línea], 59-87. <https://doi.org/10.4337/9781848445147.00009>.

PugA, D. (2004). Estrategias residenciales de las personas de edad: Movilidad y curso de vida. Barcelona: Fundación La Caixa.

Quigley, J.M. y WeInBERG, D.H. (1977). «Intra-urban residential mobility: A review and synthesis». International Regional Science Review [en línea], 2 (1), 41-66. <https://doi.org/10.1177/016001767700200104>.

RECAÑO, J. (2016). «La consolidación de las migraciones internas de inmigrantes como factor estructural de la movilidad geográfica en España». Panorama Social, 244, 49-71.

Recaño, J. y De Miguel, V. (2012). «The Internal Migration of Foreign-Born Population in Southern Europe: Demographic Patterns and Individual Determinants». En: Minority Internal Migration in Europe. Surrey: Ashgate Publishing. International Population Studies Series, 239-261.

Rossi, P.H. (1955). Why Families Moves: A Study in the Social Psychology of Urban Residential Mobility. Glencoe: Free Press.

Sabagh, G.; Van Arsdol, M.D. y Butler, E.W. (1969). "Some determinants of intrametropolitan residential mobility: Conceptual considerations». Social Forces [en línea], 48 (1), 88-98. <https://doi.org/10.1093/sf/48.1.88>.

Scanlon, K.; Whitehead, C. y Fernández Arrigoitia, M. (eds.) (2014). Social Housing in Europe [en línea]. New Jersey: John Wiley \& Sons. <https://doi.org/10.1002/9781118412367>.

SPEARE, A. (1974). "Residential satisfaction as an intervening variable in residential mobility». Demography [en línea], 11 (2), 173-188. $<$ https://doi.org/10.2307/2060556>.

SpeAre, A. y GoldSCHEIDER, F.K. (1987). «Effects of marital status change on residential mobility». Journal of Marriage and the Family [en línea], 455-464. $<$ https://doi.org/10.2307/352314>.

United Nations (2011). Canberra Group Handbook on Household Income Statistics. Ginebra.

Vono de Vilhena, D. y Bayona-Carrasco, J. (2012). «Transition towards homeownership among foreign-born immigrants in Spain from a life-course approach». Population, Space and Place [en línea], 18 (1), 100-115. $<$ https://doi.org/10.1002/psp.641>.

Wiesel, I. (2014). «Mobilities of Disadvantage: The Housing Pathways of Low-income Australians». Urban Studies [en línea], 51 (2), 319-334. <https://doi.org/10.1177/0042098013489739>. 